\title{
PONS RODRÍGUEZ, LOLA (2012). El paisaje lingüístico de Sevilla. Lenguas y variedades en el paisaje urbano hispalense. Sevilla: Diputación de Sevilla, 311 pp.
}

\author{
Simone Castellani \\ Universidad de Génova
}

La monografía de Lola Pons Rodríguez, autora con una trayectoria más que destacada en el campo de la historia de la lengua española y de la dialectología, es un trabajo que se inscribe en el cauce de los estudios socio-lingüísticos, explorando campos afines a los recorridos por los antropólogos. Ya desde el principio la autora nos deja claro cómo rastreará el terreno lingüístico en su estudio, recalcando que: "las lenguas no son simples nociones definibles en términos de gramática o estructura, son constructos levantados sobre relaciones sociales, politicas y culturales" (23).

Esta monografía dirige su mirada hacia el "paisaje lingüístico" de la capital andaluza con el propósito de poner en duda el sentido común que sostiene que Sevilla es una ciudad monolingüe, demostrando "visual y analíticamente el multilingüismo de Sevilla a través del estudio de sus espacios públicos" (4).

En la primera parte del libro, la autora nos expone de forma clara y exhaustiva su marco teórico de partida, que encuentra sus pilares en los conceptos de glocalización (Robertson, 1992) y multilingüismo. Como explica Pons, el multilingüismo es una situación de hecho que ha caracterizado la mayoría de las sociedades a lo largo de la historia. En la época contemporánea, donde las sociedades humanas están cada vez más interconectadas y atravesadas por fenómenos como las migraciones internacionales y el turismo, la convivencia entre lenguas diferentes se ha vuelto la norma. 
La autora explica que la idea de que las sociedades tienen que ser monolingües se remonta a la época medieval, cuando empiezan a tomar forma los primeros Estados modernos, y se consolida definitivamente a partir del siglo XIX, cuando se afirma el modelo del Estado-Nación. Como observaron teóricos como Hobsbawn(1998) el supuesto de que exista una única lengua que comparten todos los ciudadanos de la Nación es uno de los pilares sobre los que se apoya la ideología nacionalista. En este marco se llegó a elevar a estándar una variante lingüística presente en el territorio del Estado a través de una labor de planificación lingüística con la que se estableció la "norma" (lexical, ortográfica, etcétera), que se fue reproduciendo a lo largo de los años sobre todo a través del sistema educativo. Esta planificación implicó el olvido, el desprestigio o el veto al uso de otras lenguas y variedades de lengua, no solamente en el nivel escrito sino también en el oral, que eran de uso corriente en el territorio del Estado (23). En este sentido cabe aportar como ejemplos cercanos a la realidad española medidas como la política lingüística llevada a cabo por la dictadura franquista, con la que se prohibía el uso escrito del vasco, del catalán y del gallego en los lugares públicos, o el proceso de estigmatización que sufrieron dentro del sistema educativo variantes que diferían de la norma, como la andaluza (Trigo Cutiño, 1989).

Debajo de la ideología monolingüe subyace el supuesto de que el estado ideal para los hablantes es la condición de homogeneidad lingüística. Como observa agudamente la autora, esta ideología aún sigue viva a día de hoy, cuando se valora y se fomenta el hecho de hablar un idioma extranjero además del idioma nacional, es decir, cuando el monolingüismo parece haber dejado paso al bilingüismo. En esta postura, en efecto, se valora el aprendizaje de otro idioma sólo en términos funcionales, es decir, como oportunidad de manejo de una lengua franca a través de la cual poder comunicarse con otros habitantes del planeta (para fines de negocios, científicos, etcétera). En este marco sólo algunos idiomas (usualmente los de las ex y actuales potencias coloniales) "merecen" ser aprendidos y enseñados en las escuelas como lenguasegunda (L2): inglés, francés, español y el alemán. La abertura actual al bilingüismo, por tanto, sigue representando un intento de homogenización, dado que no representa una valorización de las diferencias lingüísticas, tanto que Pons observa que más que de bilingüismo habría que hablar de doble monolingüismo (26).

En la época contemporánea, paralelamente al fenómeno de la globalización, se articula el de la localización, que se concreta en la valorización y reivindicación de identidades locales, proponiéndose en oposición más o menos abierta a la identidad nacional y al proceso de homogenización que le subyace. Los limites étnicos de estas nuevas y viejas minorías son construidos a menudo sobre una lengua minoritaria, que suele valorizarse desde la óptica de una propuesta multiculturalista que plantea la superación de las desigualdades que se cobijan bajo el principio de igualdad a través de la puesta en valor de la diferencia (Taylor, 1992). No en vano, en los contextos donde se han llevado a cabo 
políticas multiculturalistas, como en el caso de Canadá, éstas han pasado principalmente por el reconocimiento oficial de las lenguas minoritarias (habladas por mayorías en términos numéricos en determinados territorios del Estado). Asimismo pasó en España en Catalunya, Comunitat Valenciana, Islas Baleares, Euskadi, Comunidad Foral de Navarra y Galicia donde el catalán, el vasco y el gallego fueron reconocidos como lenguas cooficiales junto con el castellano y donde hay unas políticas de planificación lingüística. No obstante, incluso estas comunidades quedan todavía lejos de ser territorios multilingües dado que, por ejemplo, las lenguas de las minorías inmigrantes no son reconocidas a la par de las lenguas oficiales, con todo lo que esto implica en términos educativos, de relaciones con la administración pública, etcétera (47).

Lo que nos enseña Pons en esta primera parte de su obra, por tanto, es que no se puede hablar de lengua y paisaje lingüístico sin tener en cuenta de la dimensión del poder. Esta dimensión resulta evidente en el "uso institucional" de la lengua: en la documentación oficial, señales de tráficos, rotulación comercial de las tiendas y locales públicos, etcétera. De hecho, el concepto de "paisaje lingüístico" empleado por la autora en esta obra nace en Canadá a finales de los años noventa, y hasta la fecha se ha aplicado mayoritariamente en investigaciones llevadas a cabo en contextos de "multilingüismo oficial", es decir, donde existe una planificación lingüística (57). El paisaje lingüístico se define como "el conjunto de realizaciones materiales del lenguaje que vemos por escrito en signos expuestos en un entorno público determinado" (55). Analizar el paisaje lingüístico en estos contextos de multilingüismo oficial significa verificar la "vitalidad etnolingüística" (58), es decir, el uso social de las lenguas dentro del contexto estudiado, poniéndolo en correlación con la planificación lingüística gubernamental. La vitalidad etnolingüística de una lengua depende de diferentes factores, como el estatus socio-económico de quienes la hablan, su composición y distribución demográfica, o el apoyo institucional (político, religioso, medio-de comunicación) del que goza (58).

El hecho de elegir analizar sólo signos escritos como elementos que componen el paisaje, tiene que ver también con la idea de que si una lengua se materializa en forma escrita llega a marcar su "existencia material", y por consecuencia la visibilidad pública de sus hablantes. Igualmente, a través de los signos escritos suelen generarse paisajes lingüísticos alternativos a los oficiales, que la autora denomina "paisaje contestados", y que se oponen a la norma lingüística y extra-lingüística: pintadas, grafitis, pancartas, etcétera...

El paisaje lingüístico, entonces, es una lente a través de la cual mirar la estructura social de un determinado territorio y observar cómo se articulan las relaciones sociales entre los hablantes de lenguas o variantes lingüísticas diferentes. No obstante, este concepto no se puede adscribir a la categorización teórica sobre paisajes acuñadas por Appadurai (1996). Desde un punto de vista socio-antropológico, la de "paisaje lingüístico" parece más bien un acercamiento metodológico para el estudio del multilingüismo en un determinado contexto territorial. 
Como evidencia Pons en el estado del arte que presenta en el segundo capítulo, en la literatura sobre paisaje lingüístico se encuentran tanto trabajos que han empleado técnicas cuantitativas, apuntando a una recopilación y categorización de las ocurrencias de signos escritos en un determinado territorio, como trabajos más cualitativos, como el que nos presenta la autora, que pretenden ahondar en el tejido social que está detrás de estos signos.

Pons defiende su elección de realizar un estudio sobre paisaje lingüístico en un contexto como el de la ciudad hispalense, donde no se da una situación de multilingüismo oficial -es decir, donde no existe una política de planificación lingüística-, ya que considera que este acercamiento metodológico resulta útil para registrar los cambios que están ocurriendo en Sevilla desde el punto de vista socio-lingüístico en la contemporaneidad. En la capital andaluza, en particular durante las últimas dos décadas, han aumentado en forma exponencial los flujos turísticos y migratorios internacionales, conjuntamente con el creciente exotismo buscado por la mercadotécnica contemporánea. Sevilla ha pasado de ser una ciudad con un alto grado de monolingüismo, impermeable a la rotulación anglófona, con la excepción de las zonas más turísticas, a tener en la actualidad un paisaje lingüístico heterogéneo (100).

En el comienzo del tercer capítulo, la autora nos presenta algunos datos demográficos sobre el contexto sevillano, poniendo de relieve la distribución de la población con nacionalidad extranjera residente en la capital andaluza, para después pasar a detallar sus elecciones metodológicas. Pons no se limita a seguir directrices ya marcadas por las investigaciones anteriores en este campo, sino que introduce algunas importantes novedades, entre las cuales la más significativa es la elección de estudiar el paisaje lingüístico de todos los barrios de la ciudad y no sólo de algunas calles o distritos.

El corpus empírico del trabajo consiste en foto-reproducciones de signos escritos sobre soportes semi-estáticos en lenguas distintas del español o variedades "geolectales" (como el español de Andalucía y el español de América) y diacrónicas (español antiguo), realizadas durante el año 2010 en todos los barrios de la ciudad. El corpus contempla signos de calles, signos publicitarios, avisos y prohibiciones, nombres de edificios, signos informativos, placas conmemorativas, objetos y grafitis (105-114).

Los resultados del análisis muestran un contexto urbano donde se da una situación de "multilingüismo asimétrico": el español no tiene competidores pero está lejos de ocupar una posición de monopolio (142). La autora clasifica las lenguas extranjeras que componenel paisaje de la ciudad hispalense en "lenguas del turismo" (inglés, francés, alemán, japonés e italiano), "leguas de la evocación" (inglés, francés, italiano y latín) y "lenguas de la inmigración" (chino, inglés, francés, ruso, ucraniano, wolof, youruba, y quechua). En el paisaje lingüístico sevillano se encuentran además dos variedades que divergen del español estándar: el andaluz y el español de América.

En las clasificaciones que estila la autora resulta particularmente importante la separación 
que instituye entre los que denomina "signos globales", de empresas o marcas que han sido transportadas hasta el paisaje lingüístico sevillano por la globalización, y los que llama "signos locales". Si a estos últimos hay que considerarlos como marcas de vitalidad etnolingüística, no puede decirse lo mismo de los primeros (148). En este sentido, por ejemplo, la presencia de las otras lenguas autonómicas reconocidas por el Estado español en el paisaje lingüístico sevillano se da sólo en términos de signos globales, más específicamente en los rótulos de las cajas de ahorro.

El cuarto capítulo está dedicado al análisis de las lenguas extranjeras más representadas en el paisaje lingüístico sevillano. En concreto se analiza la presencia del inglés (lengua del turismo y la evocación), el chino, el árabe, el italiano (lengua de la evocación) y el latín. De particular interés antropológico resulta el apartado dedicado a la lengua china, idioma que tiene una presencia importante en el paisaje lingüístico hispalense, dada la gran cantidad de comercios regidos por esta minoría en los diferentes barrios sevillanos. En el epígrafe 4.3. la autora detalla las particularidades étnico-regionales de la diáspora china en España y nos ilustra la diferencia de uso que se da dentro de la minoría china en Sevilla entre una variante regional (dialecto qintianes) y el chino mandarín. Asimismo, Pons analiza el interlingüismo que se da entre el chino y el español, dato que nos sugiere cómo se está desarrollando el aprendizaje de la lengua castellana entre la población residente procedente de china, su inserción en la realidad hispalense, y cómo se desarrolla la transmisión lingüística entre padres e hijos (estos últimos formados en el sistema educativo andaluz). Finalmente, la autora pone en evidencia la dialéctica entre lenguasque se da en elámbito de trabajo: el español se utiliza de cara a la venta mientras que el chino es usado para la búsqueda de trabajadores y traspasos de negocios. Todos estos elementos del paisaje lingüístico nos dan pistas para entender cómo se construyen y se reproducen las redes sociales chinas en Sevilla.

En el capítulo 5 la autora se centra en el análisis de las variantes del "Español Meridional”, que reúne tanto la variante andaluza como las variantes hispanoamericanas, dado que ambas originan de una "variedad de español que surgió de la extensión de una norma sevillana nacida en el Reino de Sevilla a fines del siglo XV”. En el caso de zonas de la ciudad como el barrio de la Macarena, el barrio donde se concentra la mayoría de la población latinoamericana residente en Sevilla, la autora habla de un verdadero re-encuentro entre estos dos troncos, que se originaron de la misma variedad y que se separaron hace siglos. En este apartado, el análisis lingüístico de las diferencias con el español peninsular estándar (a nivel lexical, fonético, sintáctico...) es acompañado, en la parte dedicada al español hispanoamericano, por un glosario terminológico (259-265). Particularmente llamativa resulta la reflexión sobre el uso de la variante andaluza en el paisaje lingüístico hispalense. Si por una parte, se registra un uso "involuntario", sobre todo en carteles privados, donde se evidencian los rasgos diferenciales más desprestigiados del español no estándar (p.ej. el ceceo), por otra existe un uso "deliberado", que se encuentra 
mayoritariamente en pancartas y rótulos comerciales, a través del cual se ponen en valor algunos rasgos (p.ej. el heheo) en sentido identitario (tanto para fines comerciales como transgresores) (240-243).

Lo único que hemos echado de menos en este capítulo ha sido una reflexión que se centrara específicamente en el caso del barrio de la Macarena. Este barrio, desde la época de su fuerte desarrollo en términos residenciales en los años cincuenta y sesenta, ha sido receptor de inmigrantes, primero internos (procedentes de la provincia de Sevilla y de otras provincias limítrofes) y después, durante los últimos quince años, internacionales (procedentes mayoritariamente del subcontinente latinoamericano). Por esto, desde un punto de vista antropológico, se presenta como un caso de estudio privilegiado para observar cómo conviven y se articulan diferentes variedades del español que, tanto a nivel escrito como oral, gozan de diferentes grados de prestigio y visibilidad, y en consecuencia cómo se relacionan sus hablantes en el espacio barrial. No obstante, somos conscientes de que una reflexión de este corte habría trascendido los objetivos de este trabajo.

Concluyendo, destacamos que un libro como el de Lola Pons nos enseña, por un lado, lo fructífero que sería para los antropólogos, sobre todos para los que estudian procesos migratorios, dotarse de la colaboración o el asesoramiento de un experto en el campo del estudio de la lengua. Por otro lado, y considerando el uso extenso de trabajos antropológicos que hace la autora, especialmente de los que se centran en el nivel local, nos enseña cómo el análisis y la reflexión antropológica, por su capacidad de análisis en profundidad de entorno espaciales delimitados, pueda ayudar a integrar el trabajo de otras disciplinas que se centran en la dimensión local.

\section{REFERENCIAS BILBIOGRÁFICAS}

Appadurai, Arjun (1996) Modernity At Large: Cultural Dimensions of Globalization. Minneapolis: University of Minnesota Press.

Hobsbawm, Eric (1998) Naciones y nacionalismos desde 1780. Barcelona: Crítica.

Robertson, Roland (1992) Globalization. Social Theory and Global Culture. London: Sage. Taylor, Charles (1992) The Politics of Recognition. Princeton: Princeton University Press. Trigo Cutiño, José Manuel (1989) "El habla andaluza: aspectos sociolingüísticos y didácticos”. En Almotácin, 13, pp.49-64. 